\title{
OURO BRANCO/AÇOMINAS: UM ÚLTIMO CAPÍTULO DA HISTÓRIA DA PRODUÇÃO DO ESPAÇO PARA A INDÚSTRIA?(*)
}

\author{
Heloisa S. M. Costa \& Geraldo M. Costa(**)
}

\begin{abstract}
The paper explores the close relationship between urbanization and industrialization in Minas Gerais through the case study of Açominas, a large scale steel mill built in the seventies and privatized in the eighties, and Ouro Branco, a city planned and built as its urban support. The plan of the city is first discussed in the light of national expectations concerning the expansion of that industrial branch at the time, and then compared to other previous experiences of production of space as a result of industrial needs in other areas of Minas Gerais. At the same time, some important implications are emphasized, as far as governance and the quality of the urban space are concerned.

Considering as a background the privatization of industry and a general restructuring of industrial production and goals, the paper explores some recent perspectives facing the future of both industry and the city. Some of the alternatives considered by the local leaders and administration include the diversification of activities and ecological tourism. It also argues that in a scenery of fierceful competition and constant change, the attributes of the planned urban space, despite its excludent character in social and spatial terms, are an asset that differentiates Ouro Branco from other cities in similar position.
\end{abstract}

\section{INTRODUÇÃO}

Um aspecto marcante da história da urbanização em Minas Gerais é aquele que a associa ao processo de industrialização em suas diversas fases. A produção do espaço urbano (em parte ou no todo) em função das necessidades da indústria, principalmente da monoindústria, suas implicações em termos da qualidade do espaço e do processo de gestão, bem como as perspectivas de transformações sócio-espaciais destas áreas urbanas em função da reestruturação da produção industrial em escala global, tem constituído um profícuo campo de pesquisa, envolvendo vários outros núcleos urbanos no estado.

Dentro desta abordagem, o presente trabalho busca contribuir para essa discussão a partir do estudo do caso de Ouro Branco, a última cidade planejada, em meados dos anos setenta, como base urbana de apoio à instalação de uma usina siderúrgica de grande porte, a Açominas. A cidade planejada desenvolve-se contígua ao núcleo original de Ouro Branco, situado na antiga Estrada Real que ligava o Rio de Janeiro a Ouro Preto.

Além de abordar a proposta urbanística em si, espelhada em avaliações feitas de outras cidades mineiras planejadas em momentos anteriores como suporte à siderurgia, o trabalho discute algumas das perspectivas que se colocam para o futuro, face à privatização da siderúrgica e ao redimensionamento das metas originais de produção industrial.

Assim, a busca da diversificação de atividades, a inserção no turismo histórico/ecológico, são algumas das alternativas discutidas pelas lideranças locais e regionais. Nestas, a qualidade de vida decorrente da proposta urbanística original, apesar de seu caráter segmentado e excludente, parece constituir um elemento positivo, uma vantagem comparativa, que diferencia Ouro Branco de outras áreas urbanas em situação semelhante.

\section{O PROJETO SIDERÚRGICO}

O história do projeto Açominas pode ser contada de duas formas não excludentes. Contada pela própria Açominas ou por autores por ela contratados, a decisão de implantação desta siderúrgica teria uma história antiga, que remete aos ideais dos Inconfidentes. De forma mais concreta a idéia de implantação do projeto Açominas aparece pela primeira vez no Governo Arthur Bernardes, com o primeiro plano siderúrgico nacional, que propunha "a criação de três grandes siderúrgicas: uma no Vale do Rio Doce, outra no Vale do Paraopeba e a terceira em Santa Catarina, tendo em vista as reservas de minério e de carvão do País" (Açominas 1985: 2 e 4). Decreto presidencial, datado de 09 de janeiro de 1924, autorizou a criação da siderúrgica no Vale do Paraopeba. Só em 1966, no entanto, esta siderúrgica se efetivou, por meio de iniciativa do Governo Israel Pinheiro. Não era ainda o início de sua implantação. Somente a partir de 1975/76, a Açominas começou a se concretizar, com base em decisões conjuntas dos Governos Estadual e Federal.

A partir desta data, tem início a outra forma de se contar a história da Açominas. Ou seja, passa a ter importância menor a justificativa que fala no ideal dos mineiros e na vocação de Minas Gerais para a siderurgia, para dar lugar aos planos nacionais do regime militar para a expansão da siderurgia brasileira. A siderurgia era considerada prioritária no II PND, dentro da 
estratégia essencialmente política do regime militar, de dar continuidade ao crescimento observado no período do chamado "milagre brasileiro", agora de uma forma mais planejada ${ }^{1}$. Tratava-se de uma estratégia que, como observava Lessa (1978), "colocava no centro do palco da industrialização brasileira, a grande empresa estatal" (Cf. Castro \& Souza 1985: 38).

A Açominas passa a fazer parte deste conjunto industrial, no Governo Geisel, quando o CONSIDER, em fevereiro de 1976, “considerou prioritário o Projeto Açominas para a implantação de uma usina siderúrgica de 2.000.000t/ano de aço, em seu primeiro estágio..." (Açominas 1986). A implantação deste primeiro estágio se arrastou por aproximadamente 10 anos, com a usina só entrando em operação no início de 1985.

Os seis adiamentos no cronograma de implantação no período de 1978 a 1985, são um indicador de que, pouco após ser iniciado, o projeto já não era mais prioritário. A justificativa para o hoje constatado fracasso deste projeto e de outros, a exemplo da Ferrovia do Aço, talvez esteja no que Castro \& Souza (1985) identificam como "o primado da vontade política nas decisões [econômicas] tomadas a partir de 1974” (p. 35). Além disso, analisando também o projeto Açominas, Diniz (1985) enfatiza que o aço, "com as mudanças tecnológicas contemporâneas tende cada vez mais a perder importância relativa, seja pelas mudanças na base técnica propriamente ditas, seja pela substituição por novos produtos proporcionados pelos avanços da química molecular (cerâmica, plásticos) e pelas novas ligas". Esta afirmação leva o autor a concluir que "ao eleger o projeto Açominas, o Governo de Minas estava optando pela tecnologia dominante no século XIX e não no XXI como convinha uma opção pelo futuro" (p. 103).

Todos os planos de continuidade de implantação da Açominas falharam, seja por essas razões ou por várias outras, incluindo-se aí o agravamento da crise econômica a partir do final dos anos 70. O aço produzido é semi-acabado. Os laminados acabados só seriam produzidos com a conclusão da fase seguinte, o que não ocorreu. Com estas características a Açominas foi privatizada em setembro de 1993. Recentes entrevistas com funcionários da empresa mostram que continuam as dificuldades de se ampliar a produção em termos tanto quantitativos quanto qualitativos, por meio da produção do aço acabado. Isto iria requerer novos e volumosos investimentos, que os atuais acionistas não têm como fazer.

Em relação ao mercado de trabalho, constata-se que a racionalização exigida pós-privatização resultou em dispensa de funcionários, o que veio agravar a situação sócio-econômica da população da área onde o projeto está implantado. Tal situação se soma à incapacidade estrutural dos projetos siderúrgicos em gerar efeitos multiplicadores significativos na economia, em termos tanto das relações interindustriais quanto de indução de novas atividades. Além disso, a chegada de um grande projeto desta natureza em uma região de incipiente densidade econômica e populacional, como era a região de Ouro Branco, significa impactos negativos sobre as atividades econômicas até então existentes, em especial no meio rural. Em síntese, um projeto como o da Açominas ao se instalar em determinada região, traz consigo um impacto desestruturador tanto nas relações sócio-econômicas quanto na estruturação espacial. Em seguida, novas relações e novas organizações espaciais são criadas, nos termos da funcionalidade que a operação do projeto exige. Assim, ao lado de novas oportunidades oferecidas à força de trabalho, observa-se um processo crescente de exclusão sócio-econômica e sócio-espacial, o que tem se agravado com o atual momento de globalização da economia e de mudanças nos processos produtivos $^{2}$.

Esses processos mencionados dizem respeito a um espaço mais amplo do que a cidade ou o município de Ouro Branco. A desestruturação/reestruturação econômica e sócio-espacial observada atingiu diretamente, no caso da Açominas, também os municípios de Conselheiro Lafaiete e de Congonhas, que passaram a formar, em conjunto com Ouro Branco, uma base urbana única com funções ora complementares, ora competitivas. Também, os chamados problemas urbanos resultantes dos impactos negativos do projeto Açominas, se generalizaram por este conjunto urbano.

\section{O PROJETO URBANÍSTICO: PLANEJAMENTO, UTOPIA E CONTROLE DO ESPAÇO}

O planejamento do núcleo urbano de apoio ao projeto siderúrgico foi elaborado em meados da década de setenta e deve ser entendido à luz das diretrizes e pressupostos que norteavam os planos urbanos de então. Além disto, neste caso em particular, já havia uma razoável experiência acumulada em Minas Gerais, em termos do planejamento de cidades como base urbana para a implantação de indústrias, principalmente siderúrgicas ${ }^{3}$.

De fato, desde a década de trinta, com a construção da vila operária da Companhia Siderúrgica BelgoMineira em João Monlevade, pode-se acompanhar a sistemática produção de espaços urbanos, com maior ou menor grau de autonomia, como base de apoio à

1- Não é objetivo deste artigo analisar a estratégia do regime militar naquele momento, em termos de crescimento econômico. Para mais detalhes sobre este período consultar Lessa (1978) e Castro \& Souza (1985).

2 - Ver Costa(1992) para uma visão um pouco mais aprofundada desta questão.

3 - Tal experiência remonta, de fato, às cidades mineradoras, e à necessidade de fixação de parte da força de trabalho necessária ao desenvolvimento daquela atividade. Ver, por exemplo, Pires (1996) para o caso da cidade de Nova Lima e a fixação da força de trabalho de origem inglesa empregada na Mineração de Morro Velho. 
implantação da siderurgia em Minas Gerais. A experiência prossegue nos anos quarenta, com a construção da cidade destinada a alojar a força de trabalho da Acesita - Aços Especiais Itabira - no município de Timóteo, intensificando-se no início dos anos sessenta, com o projeto e construção da cidade de Ipatinga, principal apoio urbano da Usiminas. A proximidade destas duas siderúrgicas/áreas urbanas, associada às transformações sócio-econômicas e espaciais decorrentes da implantação de projetos deste porte, fez surgir um dinâmico e complexo conjunto urbano-industrial, conhecido como Vale do Aço, que conta atualmente com cerca de 300.000 habitantes assentados em torno do maior parque siderúrgico do país, em vias de se transformar formalmente numa Região Metropolitana.

A obrigatória referência ao caso do Vale do Aço, laboratório exemplar para a discussão de processos sócio-espaciais decorrentes da produção do espaço sob a indústria, justifica-se tanto pela sua importância como registro histórico do planejamento urbano contemporâneo, como pelo fato de ter explicitamente servido de modelo (a ser seguido e a ser evitado) para o planejamento da base urbana de apoio da Açominas ${ }^{4}$.

Com efeito, a concepção do projeto urbanístico da Açominas ocorreu no mesmo período em que se desenvolvia um abrangente processo de planejamento para o Aglomerado Urbano do Vale do Aço (FJP, 1978), que evidenciava, dentre um enorme elenco de questões, a dicotomia entre as áreas planejadas e habitadas pela população diretamente ligada ao emprego formal nas usinas e o restante da(s) cidade(s), onde imperava, naturalmente, a lógica excludente de ocupação do espaço típica da nossa urbanização. A presença marcante das usinas em todas as esferas da vida e da gestão urbana, com todas as implicações daí decorrentes, era outro aspecto que permeava (e continua a permear) as análises, as propostas de intervenção, assim como as práticas cotidianas.

Estava implícita a idéia de que, tratando-se de situação bastante semelhante, qual seja, uma grande siderúrgica a ser implantada numa região de incipiente base urbana original que desencadeia a construção de uma cidade, fruto de meticuloso projeto urbanístico, as características urbanas resultantes também seriam semelhantes. Da mesma forma, os processos desencadeados pela vigorosa dinâmica urbana industrial que se estabelece na região, supunha-se, também ocorreriam na região de influência da Açominas. A menos, acreditava-se, que o planejamento pudesse evitar. Ou, pelo menos, o planejamento estaria preparado para o "inesperado". O melhor exemplo pode ser dado pelo crescimento urbano, que, no caso do Vale do Aço, em muito suplantou as projeções originais, tanto em termos das taxas demográficas obtidas, quanto da enorme extensão da área urbanizada para direções completamente inesperadas no projeto original. É curioso observar que quase duas décadas antes, também o autor do projeto urbanístico da cidade da Usiminas em Ipatinga, procurava utilizar a experiência de planejamento da cidade industrial que lhe antecedia, no caso a cidade de João Monlevade/ Belgo Mineira, para, espelhando-se nela, corrigir os "erros" e projetar as tendências de crescimento que informariam o planejamento da nova cidade industrial (Hardy Filho 1970).

Feitas estas considerações, cabe então uma breve apresentação da proposta urbanística para a alternativa selecionada, dentre um elenco de três hipóteses de localização, para constituir a base urbana de apoio à Açominas, qual seja a expansão do núcleo de Ouro Branco, uma pequena cidade de aproximadamente 4.000 habitantes, surgida durante o ciclo do ouro, a última parada antes de se chegar às minas, na Estrada Real que ligava o Rio de Janeiro à Ouro Preto. As ilustrações 1 e 2, apresentam, respectivamente, o mapa de localização regional do projeto e uma vista aérea do núcleo original de Ouro Branco.

A nova cidade deveria atender, no curto prazo, uma população de 60.000 habitantes, e, em vinte anos, as estimativas situavam-se em torno dos 180.000 habitantes, dos quais aproximadamente $90 \%$ no novo núcleo 5 (FJP 1976). Previa-se também um forte impacto nos municípios vizinhos, principalmente Congonhas e Conselheiro Lafaiete, cujas sedes municipais situavamse à 10 e $20 \mathrm{~km}$ respectivamente da planta industrial. À semelhança do Vale do Aço, previa-se a formação de um aglomerado urbano dinâmico com fortes relações de complementaridade entre os municípios (Costa 1979).

A proposta de organização espacial, adotava com rigor os princípios racionalistas do planejamento para todo o território municipal, classificado, então, segundo as seguintes áreas funcionais: área de função industrial, área de função urbana, área de função agrícola e área de função preservação. Esta última visava proteger o patrimônio ambiental representado pela Serra de Ouro Branco em termos de paisagem, flora, fauna e mananciais. Já a delimitação de um espaço agrícola traduz a preocupação com o abastecimento urbano, ao mesmo tempo que buscava garantir, através do espaço,

4 - Além do Plano de Desenvolvimento Integrado (FJP 1978) elaborado pela Fundação João Pinheiro, o Vale do Aço já foi objeto de vários tipos de estudos. No que se refere à produção do espaço sob a indústria, Costa (1979) analisa o caso no contexto da época, inclusive tendo como referência o então recém-elaborado plano para a Açominas/Ouro Branco. Para uma discussão da situação atual ver Costa (1995). Para uma análise comparativa de tres casos de produçao do espaço urbano sob a mono-indústria, à luz das transformações nas formas de organização da produção e nas relações industria/espaço urbano na região, ver (Costa \& Monte-Mór 1995).

5 - Os parâmetros adotados para as projeções foram: tamanho médio da família igual a 5,2 pessoas; relação entre população inativa e ativa de 2,6; geração de 1,8 empregos indiretos para cada emprego direto; relação entre casados e solteiros igual a $2 / 3$. 


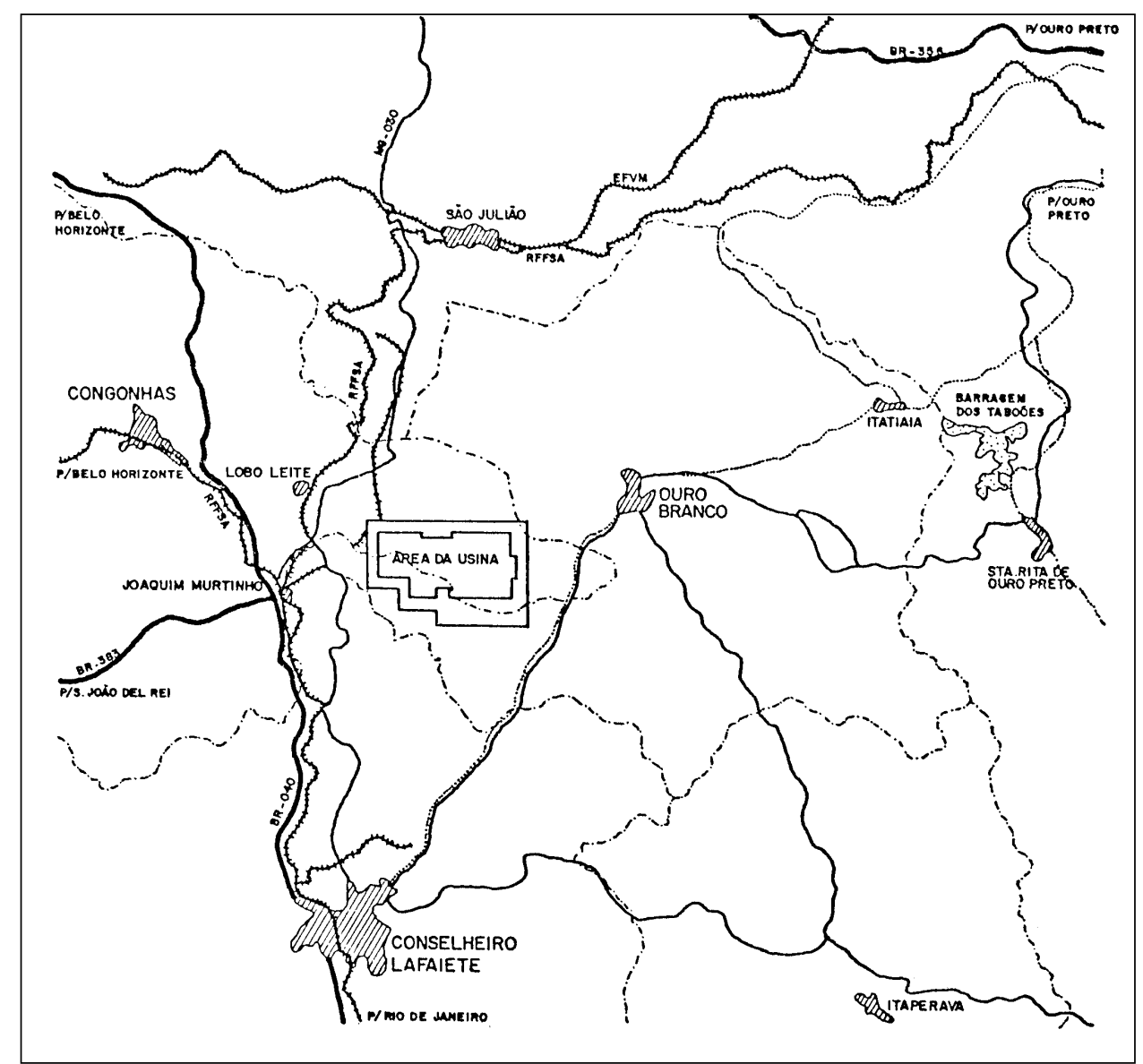

Ilustração 1: Mapa de localização regional do projeto da Açominas, fonte: Costa (1979). Ilustration 1: Regional location of Açominas project, source: Costa (1979).

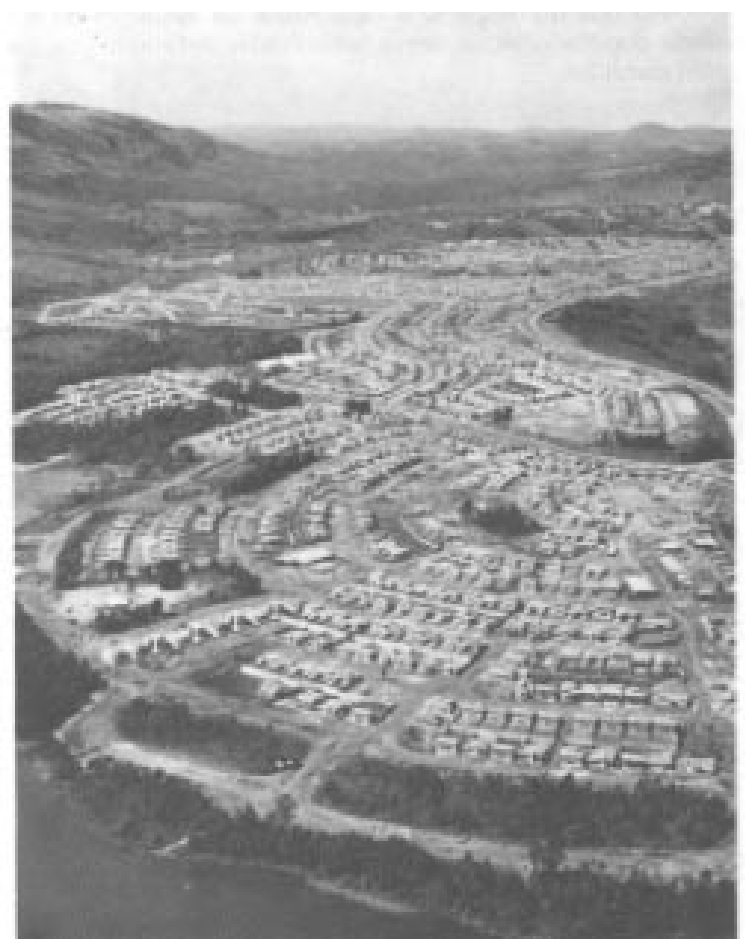

lustração 2: Vista aérea do núcleo original de Ouro Branco, fonte: Açominas (1985). Ilustration 2: View of Ouro Branco original urban nuclei, source: Açominas (1985). 
que culturas tradicionais da região (como a batata inglesa), não sucumbissem inexoravelmente à uma provável atividade imobiliária intensa que acompanharia a dinâmica industrial e urbana. Para a execução da proposta, a empresa tornou-se proprietária da quase totalidade das áreas urbana e de expansão urbana do município, garantindo assim o controle sobre o crescimento da cidade (Costa 1979: 83).

A área de função urbana parece corresponder a um planejamento impecável, com um farto sistema viário hierarquizado e dimensionado segundo critérios prevalentes de eficiência urbana, ligando os diversos setores habitacionais (de um total de 19, 10 comporiam a zona urbana e os demais a zona de expansão urbana). O uso e a ocupação destas áreas, naturalmente, foram também objeto de um acurado zoneamento funcional, segundo critérios de abrangência do atendimento dos equipamentos e serviços, sendo sua execução prevista por etapas, de certa forma associadas às fases de implantação industrial. Cabe ainda registrar que tal planejamento e execução criteriosos estenderam-se

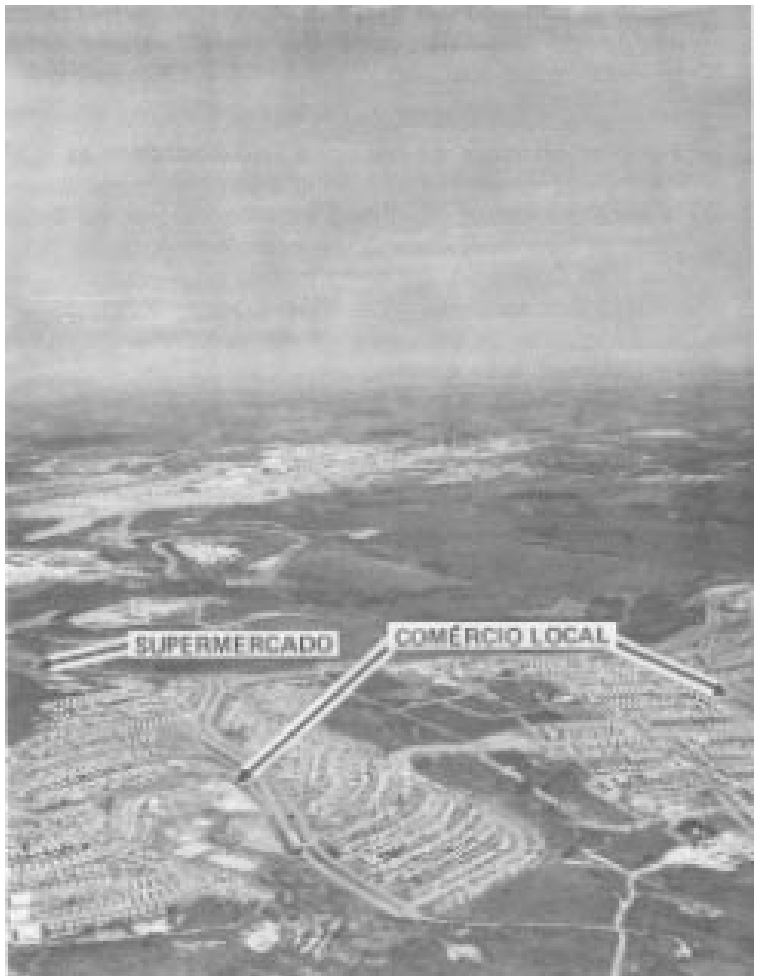

Ilustração 3: O zoneamento funcional enfatizado no documento promocional da Açominas, fonte: Açominas (1985).

Ilustration 3: Functional zoning accordingo to Açominas'promotional leaflet, source: Açominas (1985). também à infra-estrutura urbana ${ }^{6}$. As ilustrações 3 e 4, exemplificam alguns dos aspectos enfatizados do modelo de planejamento adotado.

A proposta habitacional expressa os valores e os cuidados adotados na fixação da força de trabalho necessária, elementos esses construídos à luz das experiências anteriores de implantação de cidades indústriais planejadas. Alguns aspectos explicitados pela Açominas como "filosofia" adotada pelo planejamento, merecem ser ressaltados: o primeiro revela a intenção de se construir uma "cidade-aberta" e não uma "cidade-companhia" (Açominas 1985: 6). Para se alcançar a diversidade almejada, deveria haver uma "mesclagem" na ocupação dos bairros, entre os diretamente empregados e o restante da população, numa proporção de 50\% para cada categoria. Entretanto, por razões operacionais, ligadas à necessidade de alojar imediatamente a força de trabalho indispensável para colocar em operação a primeira etapa da produção industrial, este critério foi temporariamente (e, por contingências posteriores, definitivamente) suspenso ${ }^{7}$.

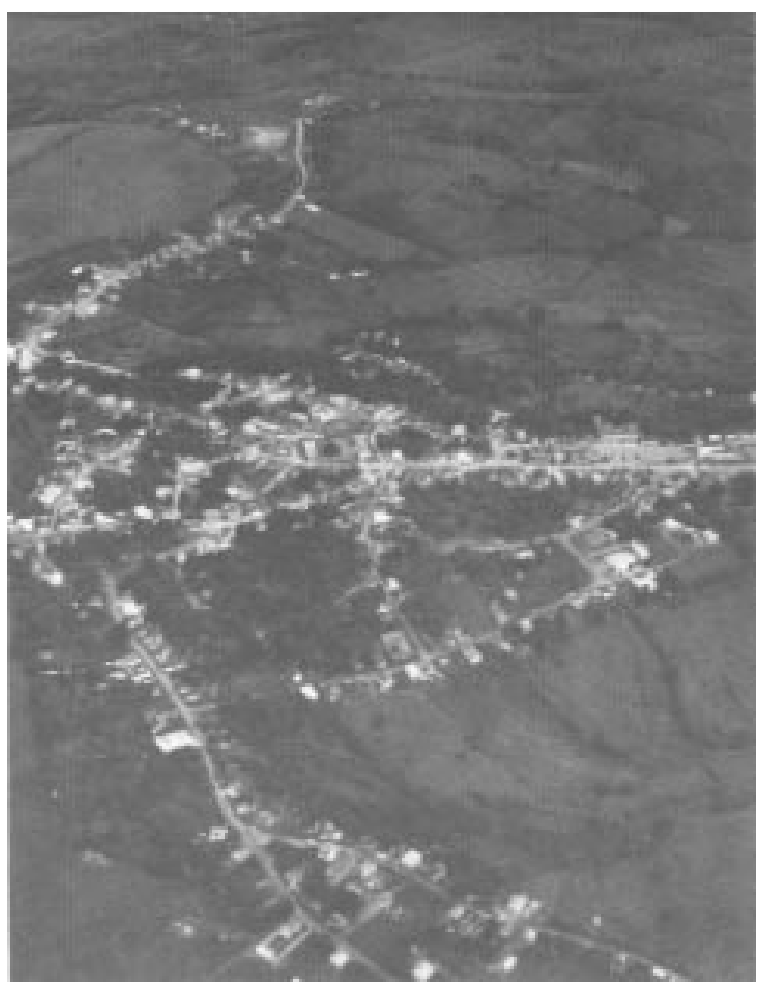

Ilustração 4: A vista aérea dos principais bairros ilutra o desenho urbano adotado no projeto, fonte: Açominas (1985).

Ilustration 4: The view of the most important neighborhoods illustrates the urban design adopted in the plan, sorce: Açominas (1985).

6- Isto não impediu, entretanto, que todo esgoto urbano, coletado em rede seja lançado sem qualquer tratamento na lagoa projetada como elemento paisagístico e de lazer para a população. Desnecessário apontar as decorrentes implicações ambientais.

7 - A título de curiosidade, deve-se registrar que esta foi a expressão utilizada pelo arquiteto Rafael Hardy $\mathrm{F}^{\circ}$. no artigo em que apresenta sua proposta para a cidade planejada da Usiminas, intitulado "Ipatinga, cidade aberta" . Naquele contexto, entretanto, "cidadeaberta" referia-se principalmente a uma posterior retirada da empresa, no caso, da Usiminas, do total controle sobre o espaço urbano, deixando espaço à iniciativa privada para atuar na cidade (Hardy Filho, 1970). Por outro lado, a idéia de "mesclagem" dentro dos bairros produzidos e controlados pela Usiminas, nunca existiu, o que sempre foi considerado um ponto negativo a ser evitado no planejamento de outras cidades industriais. 
Assim, tal qual no exemplo do Vale do Aço que se buscava suplantar, as áreas habitacionais permaneceram limitadas aos empregados diretos, reproduzindo na esfera da moradia e da sociabilidade, a segregação e as relações de poder existentes nas relações de trabalho dentro da fábrica. Isto porque, também na cidade planejada de Ouro Branco, os bairros foram projetados segundo a renda da população, o que na prática efetivamente significou uma segregação por categoria funcional já que tratava-se, de fato, de um único empregador. É interessante observar que o combate à segregação sócio-espacial em todos os níveis era uma preocupação constante dos setores mais críticos do planejamento urbano naquele momento; porém, ainda assim, o plano da nova cidade acabou por reproduzir grande parte da diferenciação que buscava evitar. Os aspectos negativos desta segregação sócio-funcional se fizeram sentir tanto em termos de problemas psicológicos associados ao meio ambiente urbano, quanto como potencializador dos conflitos inerentes às relações de trabalho ${ }^{8}$. Desta forma, nestas cidades industriais planejadas, pode-se parodiar o velho ditado para "diga-me onde moras que te direi quem és". Um outro aspecto negligenciado pelo concepção da cidade, diz respeito à não incorporação dos habitantes da Ouro Branco antiga ${ }^{9}$, assim como a precária articulação urbanística entre a cidade existente e a planejada.

O ônus da construção das moradias foi arcado pela empresa, utilizando-se de convênios e parcerias com órgãos públicos, inclusive o Sistema Financeiro da Habitação sempre que possível. O empregado tinha a opção de aquisição financiada da moradia, reservando a empresa a prioridade no caso de revenda. Tal prerrogativa foi utilizada no período inicial de implantação, como mecanismo de controle sobre o investimento já realizado em habitação, porém vem sendo abandonado nos últimos anos, o que tem proporcionado o acesso da população em geral aos bairros construídos pela Açominas ${ }^{10}$. No quadro geral de precariedade que vem marcando a qualidade da urbanização contemporânea, este fato é visto na cidade como uma melhoria de padrão social/habitacional ${ }^{11}$.

Por outro lado, não há dúvidas de que o espaço produzido é de boa qualidade. Este é um "bem", uma "vantagem comparativa", presentemente sendo usada para canalizar investimentos para o município, como se discutirá a seguir. Entretanto, a produção do ambiente construído, em seu sentido estrito, não parece ter sido suficiente para transformar um projeto urbanístico criterioso em algo mais do que uma simples "cidadecompanhia". A transcrição do primeiro objetivo almejado com o planejamento da cidade, é suficiente para demonstrar a ingenuidade da crença, muito propriamente apontada por Castells (1978), segundo a qual o espaço, por si só, teria o poder de transformar/ moldar as relações sociais. Assim, o planejamento preconizava "uma cidade saudável, humana, alegre e aconchegante, de infra-estrutura moderna, que ofereça condições para um padrão de vida compatível com o nível de renda dos empregados da AÇOMINAS, que encare todos os cidadãos igualmente e na qual a Empresa seja responsável pela criação de condições para seu desenvolvimento disciplinado e autônomo, no menor espaço de tempo possível" (Açominas 1985: 6).

A fé inabalável na capacidade do planejamento dar conta de resolver todos os impasses urbanos, desde que tivessem sido previstos, transparece no tom das publicações oficiais, bem como nas projeções feitas de crescimento urbano (tanto em termos demográficos como espaciais) da cidade e da região. Assim, enormes reservas de áreas para expansão urbana, destinadas a evitar o crescimento espontâneo e "desordenado" que fatalmente presumia-se que ocorresse na ausência do planejamento, permanecem hoje completamente vazias, apesar de parceladas e com infraestrutura, em alguns casos. São testemunhas silenciosas de expectativas que nunca chegaram a se realizar.

A rigor, a implantação do grandioso projeto siderúrgico nunca ultrapassou a primeira fase, quando seriam produzidas 2 milhões de toneladas/ano de produtos semi-acabados (note-se que a meta era atingir 10 milhões de toneladas/ano quando a siderúrgica estivesse funcionando em plena capacidade). Assim, enquanto estimava-se que a população do município atingiria 180.000 habitantes em meados da década de noventa, o Censo Demográfico de 1991 registrou uma população urbana de 23.631 para o município de Ouro Branco.

Pode-se argumentar que o caso estudado constitui um "último capítulo" da história contemporânea da

\footnotetext{
8 - Há um elevado índice de problemas psicológicos, comportamentais, sociais entre os funcionários da empresa, muitos dos quais atribuidos às condições de excessivamente interrelacionadas moradia/trabalho, típicas de "sociedades criadas artificialmente". Também nos embates trabalhistas, atribui-se uma maior agressividade aos conflitos, pela somatória de questões associadas ao status habitacional àquelas objeto de reivindicações na esfera do trabalho (Entrevista realizada com o então chefe da assessoria de planejamento da Açominas em abril de 1989).

9 - Ver Pereira (1992) para uma avaliação da percepção dos moradores da cidade acerca das transformações decorrentes da implantação da Açominas.

10- Este modelo, já utilizado com rigidez pela Usiminas desde os anos sessenta, tem feito com que aquela siderúrgica continue mantendo total controle sobre o acesso aos espaços habitacionais por ela produzidos. Mesmo após o processo de privatização, tal prática vem se mantendo (Costa 1995). 11- Esta brecha também tem sido utilizada presentemente por empregados da Açominas que procuram mudar-se para um bairro de melhor padrão urbanístico do que aquele reservado à seu status profissional dentro da empresa. Assim, além de uma mudança nos padrões de habitabilidade, há uma clara mudança de posição dentro da rígida estratificação social em vigor.
} 
produção do espaço urbano sob a grande indústria, ou seja, daquela história que associa um determinado tipo de crescimento/planejamento urbano a um modelo de industrialização de caráter fordista (mesmo que a denominação mais correta neste caso seja "grande indústria de processo contínuo"), respaldado e conduzido pelo estado, que assume a produção das condições gerais de produção e de reprodução da força de trabalho diretamente necessária ${ }^{12}$. Trata-se de um projeto que de certa forma chega atrasado no tempo, já que, em momentos mais recentes, a experiência tem mostrado que a grande indústria vem progressivamente evitando o ônus da manutenção das condições de reprodução, particularmente da construção e gestão de cidades $^{13}$. Esta nova postura de "descompromisso" para com tais condições passa a ser encarada muito mais como uma estratégia de sobrevivência das empresas face às condições atuais de competitividade.

Dentro desta perspectiva, pode-se observar uma mudança de atitude da Açominas pós-privatização, quanto à política habitacional e urbana, na direção de uma progressiva transferência do ônus da gestão urbana para a administração municipal, bem como da não ingerência sobre as transações imobiliárias nas áreas habitacionais anteriormente rigidamente estratificadas segundo critérios de renda dos moradores e de inserção no processo produtivo. Assim, a cidade planejada vai pouco a pouco se tornando mais semelhante, em termos de ocupação, às demais cidades brasileiras. Tal semelhança no plano urbanístico também começa a acontecer no campo das perspectivas econômicas. A antiga certeza decorrente da esperada expansão siderúrgica é então substituída pela necessidade de buscar na diversificação das atividades, novas alternativas de desenvolvimento.

\section{ALGUNS DESAFIOS PARA A INDÚSTRIA CONTEMPORÂNEA E SUAS CIDADES OU SERIA PARA AS CIDADES CONTEMPORÂNEAS E SUAS INDÚSTRIAS?}

Face às previsões que não se confirmaram, discutese brevemente algumas das perspectivas que se colocam para o planejamento e para a sobrevivência desta e de outras áreas industriais. Quais as possibilidades e limitações de um projeto ambicioso/fordista/ex-estatal face ao momento atual, onde a competição pela localização industrial é cada vez mais intensa?

$O$ resultado de tudo isto trouxe um clima de apreensão para a administração da cidade de Ouro Branco. A exemplo de outros casos semelhantes, foi criada recentemente a Agência de Desenvolvimento de Ouro Branco - ADOB, com o objetivo de encontrar alternativas para o desenvolvimento do município. Para isto, os dirigentes da Agência enfatizavam a importância do capital fixo existente, em especial nas formas de uma infraestrutura urbana e regional, implantada em função do projeto Açominas e de um ambiente construído urbano, do qual os bairros residenciais são o melhor exemplo. Inclui-se também neste ativo fixo, os vários galpões ociosos que poderiam ser reaproveitados para abrigar incubadoras de pequenas empresas. Este capital, é avaliado como um trunfo da cidade para atrair novos investimentos produtivos que venham diversificar a economia, percebida como dependente unicamente da siderurgia em crise, e criar novos empregos.

Não se trata de discutir as possibilidades efetivas de inserção de Ouro Branco ou de outros casos semelhantes nos circuitos mais dinâmicos da acumulação, mas sim de enfatizar uma tendência recente, a crescente e acirrada competição entre as cidades na atração de investimentos produtivos, principalmente industriais. Para utilizar o raciocínio de Harvey ${ }^{14}$, às cidades presentemente, se colocam duas alternativas na competição por investimentos produtivos: destacar-se pela permissividade ambiental e/ou nas relações de trabalho ou então sobressair-se pela qualidade de seu meio ambiente urbano. Essa última parece ser a pretensão de Ouro Branco.

$\mathrm{Na}$ visão das lideranças locais, algumas opções se colocam para diversificar a base produtiva do município. A primeira delas enfatiza a complementaridade entre ramos industriais, através da oferta de uma ampla infraestrutura disponível e ociosa para novas indústrias. Nesta linha, merece destaque a localização de Ouro Branco, praticamente à margem da BR-040, a pouco mais de $100 \mathrm{~km}$ de Belo Horizonte, como uma evidente vantagem comparativa. Até o momento, aparentemente tal vantagem não foi ainda suficiente para se materializar em investimentos produtivos para o município.

12 - Foge do escopo deste trabalho uma discussão mais aprofundadadas características da industrialização contemporânea, por alguns denominada pós-fordista, bem como suas implicações espaciais. Tem-se como referência, entretanto, os trabalhos de Castells (1986), Boddy (1980), Conti (1995) e Dicken et al. (1995). Para uma análise das áreas industriais dinâmicas no Brasil, ver Diniz \& Crocco (1996).

13 - Aproximadamente no mesmo período (final da década de setenta) outras indústrias ao se implantarem em Minas Gerais, já adotam uma posição muito mais "flexível" com relação ao provimento das condições de reprodução da força de trabalho. Ver Costa (1995) para um estudo do caso da Cenibra - Celulose Nipo-Brasileira - que por um lado busca equacionar a questão da acessibilidade da força de trabalho à fabrica através da mobilidade pendular diária e, por outro lado, utiliza largamente o expediente da terceirização entre outras formas de inserção parcial e/ou temporária no trabalho industrial. Ver também o trabalho de Borba (1995) para um interessante estudo comparativo sobre cidades industriais gaúchas.

14 - Estas idéias foram desenvolvidas em uma conferência realizada por David Harvey em Belo Horizonte, em 1995. 
A segunda opção busca aproveitar o pequeno capital local e regional, inclusive aquele proveniente de indenizações por demissão de ex-funcionários da Açominas (uma vez desvinculados da empresa, muitos ex-funcionários se deparam com o dilema de encontrar um motivo para permanecer na cidade). A criação de "incubadoras de empresas", ou seja, pequenas empresas, lastreadas no mercado local, mas não apenas, que necessitam de um apoio em termos de infraestrutura inicial, ocupando galpões anteriormente usados como alojamento de recém-chegados à cidade, tem sido apresentada como um caminho com potencial a ser melhor explorado. Até que ponto a diversificação econômica pode ser construída a partir de iniciativas como esta, não é possível prever nem cabe avaliar no momento.

Outras alternativas, ainda timidamente exploradas, que não excluem as primeiras, caminham numa direção que vem sendo crescentemente perseguida por outras cidades, qual seja, a de apostar no turismo históricoecológico: explorar a imagem de cidade com boa qualidade de vida, boa infra-estrutura, localização privilegiada, associada a aspectos históricos, que se torna então imprescindível resgatar, além do importante patrimônio ambiental e paisagístico representado pela Serra de Ouro Branco. Dentro desta perspectiva, o asfaltamento da estrada que liga a cidade a Ouro Preto seria uma pré-condição. O valor intrínseco da qualidade do meio-ambiente construído reaparece como uma vantagem, quando a alternativa de uma maior proximidade com o núcleo histórico de Ouro Preto é apontada como um elemento que supriria as carências de educação superior existentes em Ouro Branco, transformando a cidade numa opção de moradia para amplos setores da população.

É sem dúvidas uma ironia que bairros industriais passem a ser não só uma mercadoria desejável, como um trunfo para atrair camadas de maior renda da população. Somente a carência habitacional generalizada e a exigüidade de investimentos na melhoria das condições de habitabilidade das cidades brasileiras faz com que aquilo que deveria ser a regra um ambiente construído dentro de padrões aceitáveis de qualidade - seja a exceção.

\section{REFERÊNCIAS BIBLIOGRÁFICAS}

AÇOMINAS, 1985. A cidade / a usina. Açominas, Belo Horizonte. (Documento promocional).

BISPO,R.C.M., 1990. Impactos sócio-econômicos e populacionais de grandes projetos industriais no meio urbano: um estudo de caso. Monografia de Graduação, Departamento de Geografia, IGC/UFMG.
BODDY,M., 1990. Reestruturação industrial, pós-fordismo e novos espaços industriais: uma crítica. In: VALLADARES,L.P.\& PRETECEILLE,E. (coords.) Reestruturação urbana: tendências e desafios. Nobel/ IUPERJ, São Paulo, p. 44-58.

BORBA,S.V., 1995. Estruturação intra-urbana em cidades industriais do Rio Grande do Sul. Anais do VI Encontro Nacional da ANPUR. ANPUR, Brasília, p. 572-584.

CASTELLS,M., 1978. City, class and power. The Macmillan Press, London.

CASTELLS,M., 1986. Mudança tecnológica, reestruturação econômica e a nova divisão espacial do trabalho. Espaço \& Debates, n.17, São Paulo.

CASTRO,A.B.\& SOUZA,F.E.P., 1985. A economia brasileira em marcha forçada. Paz e Terra, Rio de Janeiro.

CONTI,S., 1995. Global-local Perspectives. A review of concepts and theoretical proposals. Trabalho apresentado na Conferência Anual da União Geográfica Internacional, Seul, Coréia do Sul, mimeo.

COSTA,G.M., 1979. O processo de formação do espaço das cidades mono-industriais. Dissertação de Mestrado, COPPE/UFRJ, 95 p.

COSTA,G.M., 1992. Impactos de grandes projetos industriais: desorganização/reorganização espacial de processos econômicos e populacionais. Anais do VIII Encontro Nacional da ABEP. v.3. Abep, Campinas, p. 43-63.

COSTA,H.S.M., 1995. Vale do Aço: da produção da cidade moderna sob a grande indústria à diversificação do meio-ambiente urbano. Tese de Doutorado, Cedeplar/UFMG, 291 p..

COSTA,H.S.M.\& MONTE-MÓR,R.L.M., 1995. Cidades industriais planejadas e a exclusão da força de trabalho. Anais do VI Encontro Nacional da ANPUR. ANPUR, Brasília, p. 420-430.

DICKEN,P.;PECK,J.;TICKELL,A.; 1995. Unpacking the global. Trabalho apresentado na Conferência Anual da União Geográfica Internacional, Seul, Coréia do Sul, mimeo.

DINIZ,C.C., 1981. Estado e capital estrangeiro na industrialização mineira. UFMG/PROED, Belo Horizonte.

DINIZ,C.C., 1988. Minas Gerais na divisão inter-regional do trabalho no Brasil: alterações recentes e perspectivas. Anais do IV Seminário sobre a economia mineira, CEDEPLAR/UFMG, Diamantina.

DINIZ,C.C.\& CROCCO,M.A., 1996. Reestruturação econômica e impacto regional: o novo mapa da indústria. Nova Economia, v.6, n.1, Belo Horizonte, p. 77-104.

FJP, 1976. Açominas. Termo de referência para ocupação do solo. Fundação João Pinheiro, Belo Horizonte.

FJP, 1978. Plano de Desenvolvimento Integrado do Aglomerado Urbano do Vale do Aço. Fundação João Pinheiro, Belo Horizonte.

HARDY FILHO,R., 1970. Ipatinga, cidade aberta. Usiminas Revista, 1(2): 34 .

MONTE-MÓR,R.L.\& COSTA,H.S.M., 1996. Inovações tecnológicas e novas espacialidades: evidências e tendências recentes. Trabalho apresentado no XX Encontro Anual da ANPOCS. Caxambu.

PEREIRA,D.B., 1992. Açominas; uma paisagem industrial na percepção dos moradores de Ouro Branco. Dissertação de Mestrado, IGC/UFMG.

PIRES,C.T.P., 1996. Influência inglesa em Nova Lima: construção de uma cidade, de um modo de vida. Trabalho apresentado no IV Seminário sobre História da Cidade e do Urbanismo. PROURB/UFRJ, Rio de Janeiro.

SOUZA,M.A.G., 1985. Açominas; aspiração de várias gerações de mineiros. Aço Minas Gerais, Belo Horizonte. 